\title{
Erratum to: Chromatin remodeling factor LSH affects fumarate hydratase as a cancer driver
}

Shuang Liu and Yong-Guang Tao $1,2,3^{*}$

\section{Erratum to: Chin J Cancer (2016) 35:72 DOI 10.1186/s40880-016-0138-7}

After publication of this article [1], the editor noticed two errors in Figure 1. The word "Vemintin" should be
"Vimentin" and "E-caderin" should be "E-cadherin". The correct version of Fig. 1 can be found in this erratum.

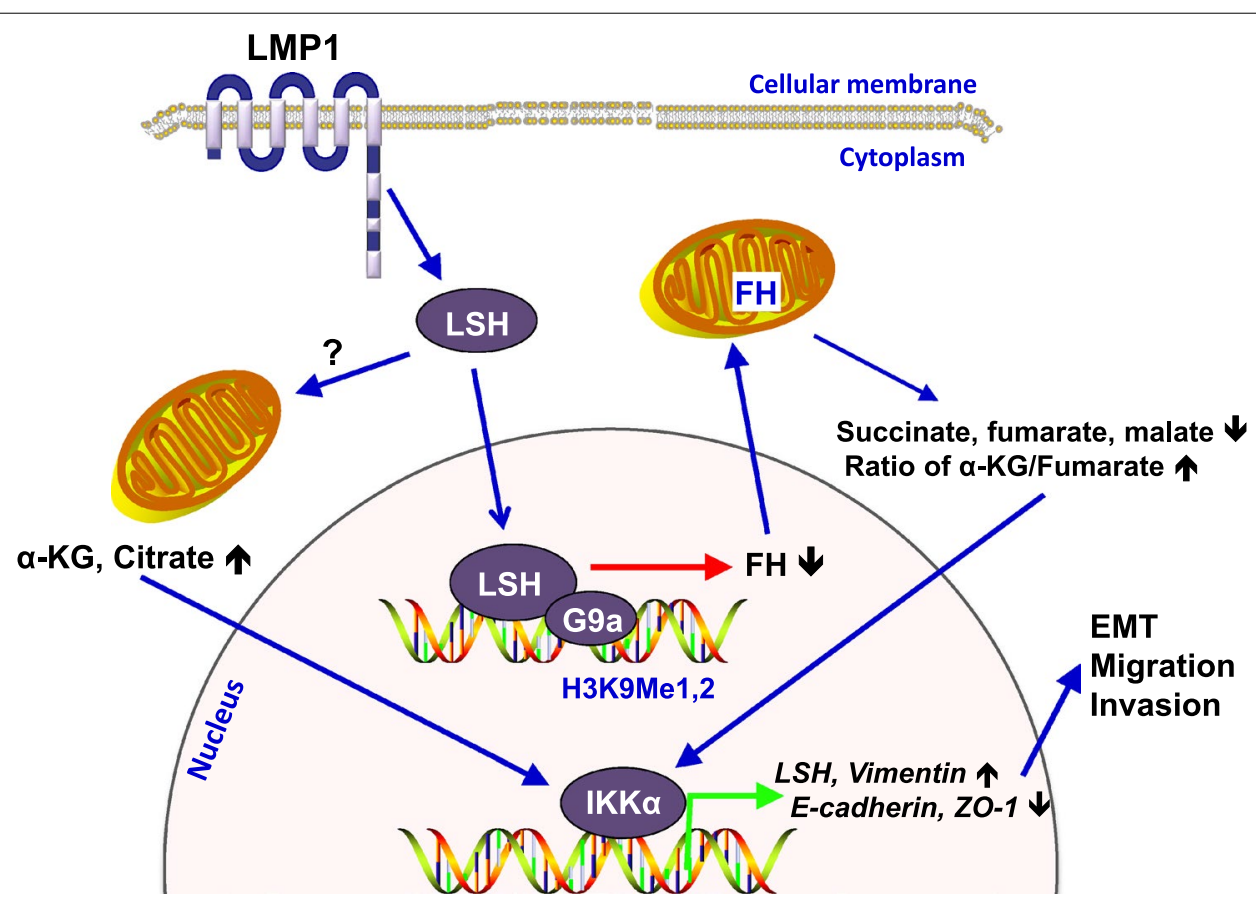

Fig. 1 Schematic model of lymphocyte-specific helicase (LSH) in cancer progression. LSH promotes cell growth, migration, and invasion, which are characteristics of cancer progression. The effect of LSH is, in part, mediated by fumarate hydratase (FH), through the intact combination of LSH and euchromatic histone-lysine N-methyltransferase 2 (G9a). FH repression, in turn, leads to changes of tricarboxylic acid cycle (TCA) intermediates, including succinate, fumarate, and malate, and an increase in the ratio of a-ketoglutarate ( $\mathrm{a}-\mathrm{KG}$ ) to fumarate. TCA intermediates promote migration, invasion, and epithelial-mesenchymal transition (EMT) through the decrease of E-cadherin and tight junction protein ZO-1 and the increase of vimentin. The changes of E-cadherin and ZO-1 are mediated by inhibitor of nuclear factor kappa-B kinase alpha (IKKa), which directly binds to these promoters

\footnotetext{
${ }^{*}$ Correspondence: taoyong@csu.edu.cn

${ }^{1}$ Center for Medicine Research, Xiangya Hospital, Central South

University, Changsha 410008, Hunan, P. R. China
}

Full list of author information is available at the end of the article provided you give appropriate credit to the original author(s) and the source, provide a link to the Creative Commons license, and indicate if changes were made. The Creative Commons Public Domain Dedication waiver (http://creativecommons.org/ publicdomain/zero/1.0/) applies to the data made available in this article, unless otherwise stated. 


\section{Author details}

${ }^{1}$ Center for Medicine Research, Xiangya Hospital, Central South University, Changsha 410008, Hunan, P. R. China. ${ }^{2}$ Cancer Research Institute, School of Basic Medicine, Central South University, Changsha 410078, Hunan, P. R. China. ${ }^{3}$ Key Laboratory of Carcinogenesis and Cancer Invasion (Central South University), Ministry of Education, Changsha 410078, Hunan, P. R. China.

The online version of the original article can be found under doi:10.1186/s40880-016-0138-7.
Received: 3 November 2016 Accepted: 3 November 2016

Published online: 28 November 2016

\section{Reference}

1. Liu S, Tao YG. Chromatin remodeling factor LSH affects fumarate hydratase as a cancer driver. Chin J Cancer. 2016;35:72. doi:10.1186/ s40880-016-0138-7. 